UCRL-ID-131584

\title{
Galvanic Corrosion Testing Using Electrochemical and Immersion Techniques
}

\author{
Ajit Roy
}

July 9, 1996

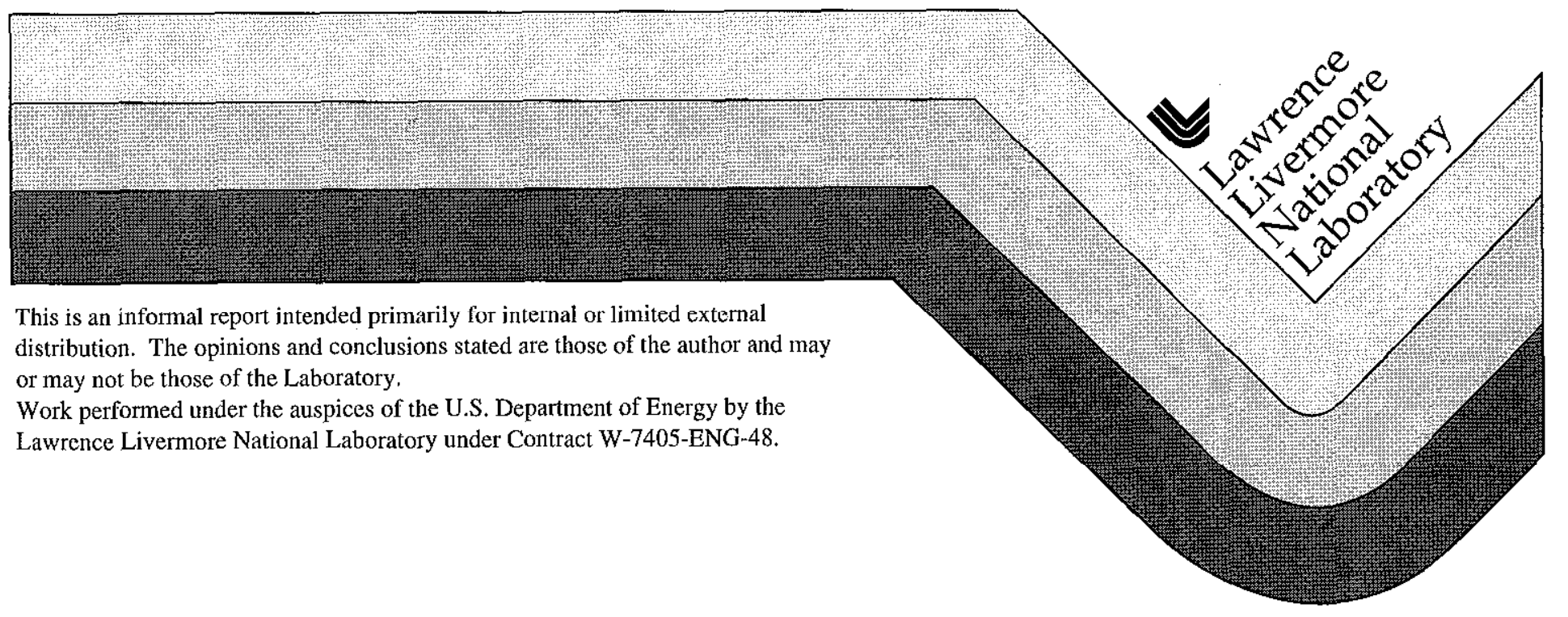




\section{DISCLAIMER}

This document was prepared as an account of work sponsored by an agency of the United States Government. Neither the United States Government nor the University of California nor any of their employees, makes any warranty, express or implied, or assumes any legal liability or responsibility for the accuracy, completeness, or usefulness of any information, apparatus, product, or process disclosed, or represents that its use would not infringe privately owned rights. Reference herein to any specific commercial product, process, or service by trade name, trademark, manufacturer, or otherwise, does not necessarily constitute or imply its endorsement, recommendation, or favoring by the United States Government or the University of California. The views and opinions of authors expressed herein do not necessarily state or reflect those of the United States Government or the University of California, and shall not be used for advertising or product endorsement purposes.

This report has been reproduced directly from the best available copy.

Available to DOE and DOE contractors from the

Office of Scientific and Technical Information

P.O. Box 62, Oak Ridge, TN 37831

Prices available from (423) 576-8401

Available to the public from the National Technical Information Service

U.S. Department of Commerce 5285 Port Royal Rd., Springfield, VA 22161 
University of California

Lawrence Livermore

National Laboratory

YUCCA MOUNTAIN PROJECT

Activity Plan
No.:

Revision: $\quad 0$

Change Notice:

Page:

AUTHOR:

Galvanic Corrosion Testing Using Electrochemical and Immersion Techniques

Training Required: Yes $\square$ No $\square$

Comments:

N/A

REVISION HISTORY

Rev. No. CN No. Effective Date Description of Revision/CN

0

$7 / 9 / 96$

Original issue.

$E-20-46$

N/A

of

17
Subject:

$7 / 9 / 96 \quad$ Original issue.

APPROVALS:

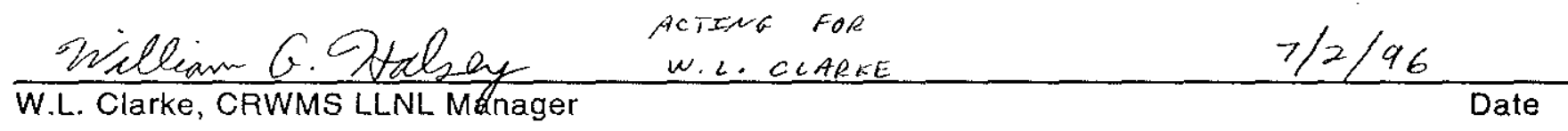

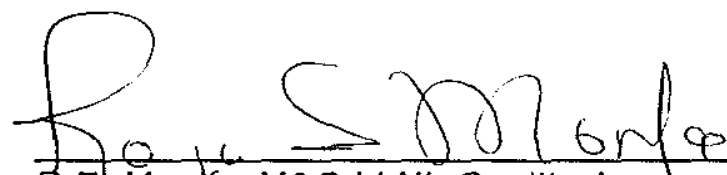

R.E. Monffs, M\&O LLNL Quality Assurance Manager

$7 \cdot 2 \cdot 96$

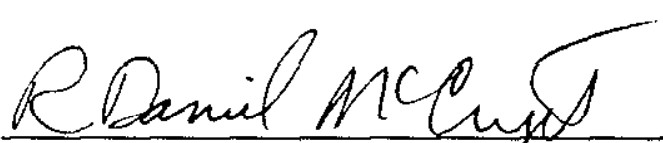

R.D. McCright, Technical Area Leader 
Activity Plan E-20-46

Galvanic Corrosion Testing Using Electrochemical and Immersion Techniques

\begin{tabular}{c}
\hline YMP WBS Element 1.2.2.5.1 \\
LLNL-YMP Metal Barrier Selection and Testing \\
\hline
\end{tabular}

Lawrence Livermore National Laboratory

Revision 0

Effective Date: $7 / 9 / 96$ 
1.0 SCIENTIFIC INVESTIGATION PLAN ..............................

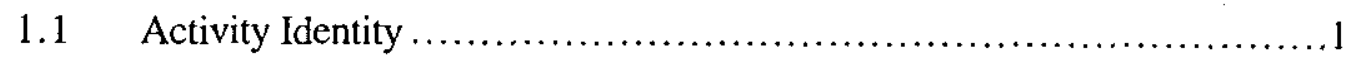

1.2 Responsibilities .................................................

2.0 SCOPE, PURPOSE, AND OBJECTIVES $\ldots \ldots \ldots \ldots \ldots \ldots \ldots \ldots \ldots \ldots \ldots \ldots$

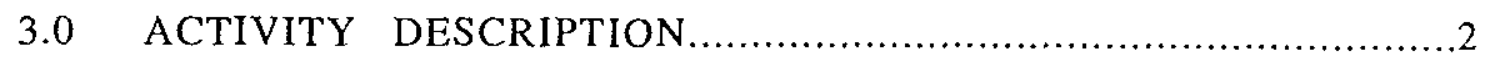

3.1 Electrochemical Aspect of Galvanic Corrosion...............................2

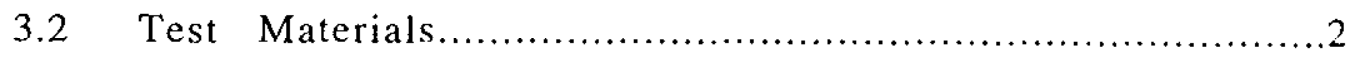

$3.3 \quad$ Test Environments ................................................ 3

$3.4 \quad$ Experimental Procedure ........................................... 4

3.5 Technical and Readiness Reviews .................................4

3.6 Hold Points ......................................................

3.7 Special Training/Qualification Requirements ...........................5

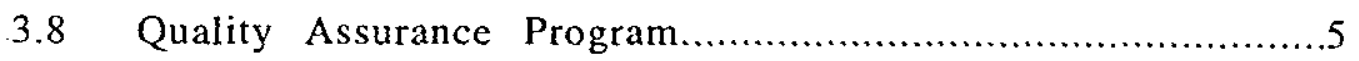

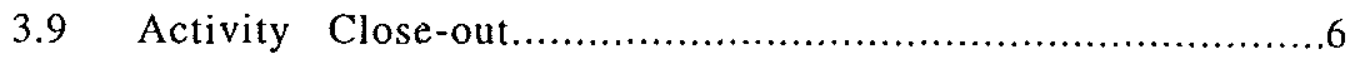

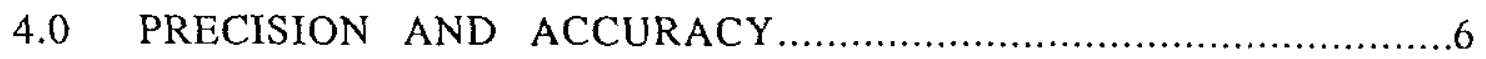

4.1 Calibration Requirements ...........................................6

4.1.1 Potentiostat and Electrochemical Test Cell .....................6

4.1 .2 Test Solutions .......................................... 7

4.1.3 Other........................................................

4.2 Sources of uncertainty and error to be controlled and measured ..........7

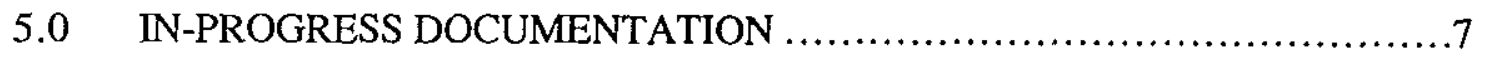

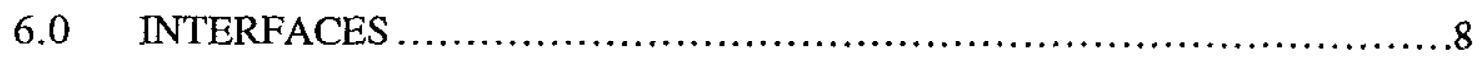

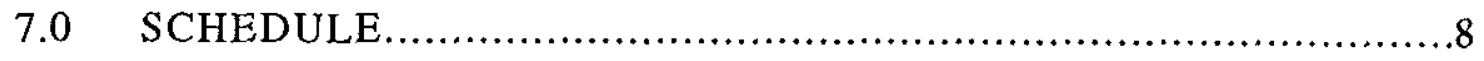

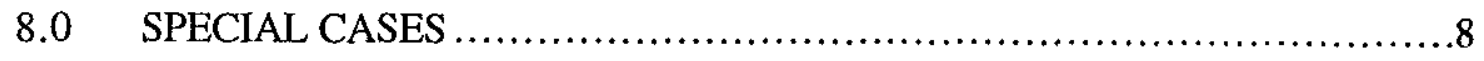

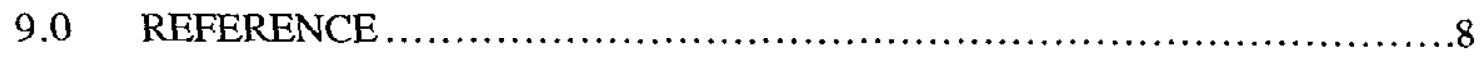

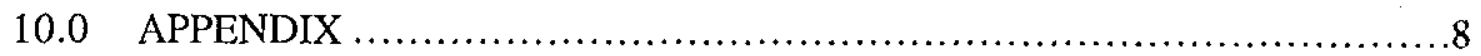




\section{LIST OF TABLES}

Page

Table 1 List of Materials Recommended for Testing ........................ 9 


\section{LIST OF FIGURES}

Page

Figure 1 Electrochemical Test Setup to Measure Galvanic Current...................10 
This activity plan is prepared in accordance with Lawrence Livermore National Laboratory (LLNL) Yucca Mountain Project procedure 033-YMP-QP 3.0, "Scientific Investigation Control." This plan is written for activity E-20-46, entitled "Galvanic Corrosion Testing," which is a part of the Scientific Investigation Plan (SIP) "Metal Barrier Selection and Testing" (SIP-CM-01, Rev 2, CN SIP-CM-01-2-1).

\subsection{Activity Identity}

The activity E-20-46 entitled "Galvanic Corrosion Testing," is a newly-developed activity, and will involve both short-term and long-term Abiotic Laboratory Corrosion Testing described in the SIP "Metal Barrier Selection and Testing." As described in SIP-CM-01, Rev 2, CN SIP-CM-01-2-1, this activity will evaluate galvanic corrosion behavior of candidate waste package container materials using a short-term electrochemical technique and a long-term immersion method.

\subsection{Responsibilities}

Key personnel responsible for performing the work in this activity are:

Technical Area Leader: Engineered Barrier Materials

Lead Principal Investigator: Electrochemical Testing
Dr. R.D. McCright

Dr. A.K. Roy

\subsection{SCOPE, PURPOSE, AND OBJECTIVES}

The current waste package design effort is focused on all-metallic multi-barrier concepts to accommodate canistered spent fuel, uncanistered spent fuel, and defense high-level waste glass canisters. This design incorporates an outer corrosion-allowance metal barrier over an inner container made of suitable corrosion-resistant metal. The corrosion-allowance barrier, which will be thicker than the inner corrosion-resistant barrier, is being designed to undergo corrosion-assisted degradation at a very slow rate, thus providing the inner container protection from the potential repository environment for an extended duration.

While the precise method of fabricating these multi-barrier waste packages is yet to be finalized, two alternate approaches are currently being considered. One approach is to fabricate these two metallic barriers separately, and then to slip the inner barrier into the outer. Under this scenario, assuming breaching of the outer container, crevice corrosion will occur at the line of contact between these two containment barriers during horizontal emplacement inside the potential repository. The tendency to undergo crevice corrosion can, however, be prevented by maintaining a larger gap between the inner and outer container by placing a spacer in between them. Under this design configuration, it is likely that the more electronegative outer container material may undergo increased corrosion, thus protecting the more noble inner barrier material. 
The alternate method is to fabricate the waste packages from clad or weld-overlay materials. In this case, the outer corrosion-allowance metallic barrier will have a thin layer of corrosion-resistant clad material inside, thus eliminating the gap between the two barriers while still providing galvanic protection to the more noble material.

While a wide variety of degradation modes can occur in aqueous environments for waste package container materials, galvanic corrosion of the outer corrosion-allowance metallic barrier is considered to be one important mode. Accelerated corrosion of the outer container may occur because of its galvanic contact with the more noble inner container while exposed to a common electrolytic solution resulting from the breaching of the outer container. The proposed activity is concerned with the evaluation of galvanic corrosion behavior of many different metallic couples in repository-relevant aqueous environments, by measuring current between two dissimilar metallic materials and observation of the corrosion of clad metallic couples.

\section{$3.0 \quad$ ACTIVITY DESCRIPTION}

\subsection{Electrochemical Aspect of Galvanic Corrosion}

The electrochemical techniques for predicting galvanic corrosion consist of either development of a galvanic series in the environment of interest, or generation of both cathodic and anodic polarization curves for materials of interest in a similar environment. A galvanic series lists the metals of interest in order of their corrosion potentials, starting with the most active (electronegative) and proceeding in order to the most noble (electropositive). Use of a galvanic series provides only a qualitative prediction of galvanic corrosion. No information, however, is available for quantitative predictions of corrosion rate from this approach.

More useful information on the rate of galvanic corrosion can be obtained by investigating either the potentiodynamic or potentiostatic polarization behavior of the materials involved. Of these two methods, the former one is particularly effective for materials with timeindependent polarization behavior, and provides a reasonable and quantitative prediction of corrosion rates. Polarization under the influence of galvanic coupling can be treated by the application of the mixed potential theory. This theory is based on two simple hypotheses: (1) any electrochemical reaction can be divided into two or more oxidation and reduction reactions, and (2) there can be no net accumulation of electrical charge during an electrochemical reaction. When equal areas of two dissimilar metals, say A and B, are electrically coupled in a common electrolyte, both metals are polarized so that each corrodes at a new rate, and the resultant mixed potential of the system (i.e. $E_{\text {corr.AB }}$ ) is at the intersection where the total rate of oxidation equals the total rate of reduction.

\subsection{Test Materials}

A list of materials recommended for galvanic corrosion testing is shown in Table 1. Wrought carbon steel (A 516 Grade 55), Alloy 400, and 70/30 Cupronickel will be used as anodes, and will be galvanically coupled to highly corrosion-resistant materials which will act as cathodes. While wrought carbon steel is the current primary choice for corrosionallowance outer barrier material, Alloy 400 and CDA 715 are also being considered to mitigate microbiologically-influenced corrosion. It should be noted that the materials identified in Table 1 are of current interest, and that this list may be modified later as work progresses in the Waste Package Design and Waste Package Materials areas. 
Because test specimens, machined to shapes and dimensions, are readily and commercially available, these will be used for nearly all of the planned work. The vendor of these specimens provides an analysis of the material generally taken from the "heat," that is, the ingot from which the lot of specimens was machined. Thus, specimens from the same batch will have the same compositional analysis, and this is advantageous since the main intent of this investigation is comparison of different alloys. In the case where special materials are needed, such as materials with different process histories (e.g. heat treatments) or special compositions, the source and description of these materials will be indicated in the scientific notebook.

Because of the small size of test specimens and the nature of this kind of testing, identification numbers will NOT be inscribed, engraved, or stamped onto the metal surfaces. These actions would seriously compromise the data obtained in this study. However, identification will be maintained on the sample bag or envelope used for storing the test specimen. When not in test, specimens will be stored in a dry environment and in a manner not likely to damage the surface.

\subsection{Test Environments}

Although the groundwater in the vicinity of the proposed repository (Well J-13) is known to have a near-neutral to slightly alkaline $\mathrm{pH}$, and to be benign to corrosion-resistant materials, initial testing will be performed at three different temperatures (ambient, $60^{\circ} \mathrm{C}$ and $90^{\circ} \mathrm{C}$ ) in four aqueous environments, as indicated below:

- Simulated groundwater (similar to J-13 well water)

- Concentrated groundwater (20-100 times J-13 well water ionic concentration)

- $\quad$ Acidified, concentrated groundwater ( $\mathrm{pH} 2-3$ )

- $\quad$ Alkalized, concentrated groundwater ( $\mathrm{pH} \sim 10-12)$

The neutral, concentrated groundwater would simulate a dry-out condition followed by resaturation, causing concentration of ionic salts. An acidified, concentrated groundwater would represent an extreme case in which microbial corrosion may occur as a result of reactions between certain man-made materials (diesel fuels, organics, and sulfur-containing compounds) and water. These materials may be introduced into the repository during construction and operation, and may not be removed or may be inadvertently left behind when operations cease. The acidic $\mathrm{pH}$ can also simulate some of the effects of radiolysis. The alkalized, concentrated groundwater would simulate reactions between man-made materials such as concretes or grouts, which may be used in construction of emplacement drifts, and the aqueous environment.

Following the study on the effects of $\mathrm{pH}$, chloride ion concentration, and temperature on galvanic corrosion, the effects of other ionic species generally present in the geochemical environments associated with the proposed repository will be evaluated. These species include sulfate, nitrate, bicarbonate, and fluoride. Also, the effects of ions, particularly ferric, that result from corrosion of the steel mesh and supports in the repository or from the outer barrier of the waste package will be studied. Because of the large number of variables that ultimately need to be investigated, this activity may require a few years to complete. Where feasible, factorially-designed experimental approaches will be used to evaluate the combined effects of different variables. 
Test solutions will be made from distilled water and reagent grade chemicals, following standard laboratory practices. Significant details of the solution preparation will be kept in the appropriate scientific notebook.

\subsection{Experimental Procedure}

There is no standard immersion test method for galvanic corrosion evaluation. However, for non-clad specimens, immersion testing planned in this program will involve an electrical connection with a wire (passing through a sensitive current-measuring device) between two dissimilar metals of similar wetted or exposed area. The relative wetted surface areas of materials being tested and their distance will have significant effects on the magnitude of the galvanic attack. The larger the cathode-to-anode area ratio, and the closer together they are, the greater the attack will be. Measurement of electrical current flowing between these two metals can give a very sensitive indication of the extent of galvanic attack, and will allow the attack to be monitored over time. Current will be measured by using a zero-resistance ammeter, which is an operational amplifier connected to maintain zero voltage across its input terminals (Figure 1). The electrolyte will be excluded from the area of contact between the electrode and the wire by applying a sealant, such as silicone, epoxy or paint, or by keeping the joint area out of the electrolyte by partial immersion of the specimen, in which case a waterline area will be created.

EG\&G Models 273 and 283 potentiostats, computer-controlled with EG\&G Models $252 / 352$ Softcorr II software, will be used as zero-resistance ammeters to measure the current characteristics of a system consisting of two dissimilar metals immersed in a test solution. Since two working electrodes are involved in galvanic corrosion testing, and a counter electrode is unnecessary, a Pyrex corrosion cell will be developed in-house to contain these working electrodes and a reference electrode (saturated calomel or $\mathrm{Ag} / \mathrm{AgCl}$ ). Cell connections will be made according to the operating instructions provided by EG\&G. The results will be displayed on the computer monitor as either current density vs time, or potential vs time, and will be saved and printed upon completion of testing.

The immersion technique described above cannot be applied to measure galvanic current between two dissimilar clad or weld-overlay metals or alloys, since they would be shorted together. Instead, small sections of clad assembly consisting of both corrosion-resistant and corrosion-allowance materials will be exposed to test solutions (aerated and deaerated) for periods ranging from one to six months. At the conclusion of each test, the specimens will be examined visually and microscopically to determine the extent of damage in each individual material and the welded region.

\subsection{Technical and Readiness Reviews}

No additional formal Readiness Review (QP 2.6) is planned for this activity. No formal technical review (QP 2.4) is planned at the completion of the present activity. However, depending on the progress of technical work in this activity and related ones, a technical review may be held to review the adequacy of the galvanic corrosion testing for making long-term performance predictions. 


\subsection{Hold Points}

The operation of the testing facility will be monitored on a continuous basis by the Lead Principal Investigator to ensure that the work is proceeding according to plan. If significant unanticipated problems arise, the Lead Principal Investigator will inform the Technical Area Leader. A joint decision will be made about the future course of action.

The progress of testing will be reported to the Technical Area Leader in periodic reports. If substantial changes in project scope require that experimental work change significantly in direction, the Technical Area Leader will communicate this to the Lead Principal Investigator in writing. No formal hold points or decision points will be designated.

\subsection{Special Training/Qualification Requirements}

Qualifications of the Principal Investigator(s) and technicians are specified by the Technical Area Leader in accordance with 033-YMP-QP 2.10, "Qualification of Personnel." A Principal Investigator (PI) shall have a Ph.D. or equivalent in materials science, metallurgy, metallurgical engineering, corrosion engineering, or related field. Technical support staff shall have experience in electrochemical or corrosion instrumentation and techniques. Only personnel trained to appropriate quality procedures and any other procedures of the Yucca Mountain Site Characterization Project will be allowed to participate in these activities. Assignment of personnel may change with time. Names of personnel authorized to perform the experimental work in this activity are given in the appropriate scientific notebook. The current position descriptions, management certifications, and QA training records should be consulted for more details.

\subsection{Quality Assurance Program}

This activity will comply with all procedures that are prescribed by the procedure 033 YMP-QP 2.8, "Quality Assurance Grading." This activity will be monitored for compliance through surveillance.

In particular, certain parts of the QP manual that will be followed are as follows:

1. Measurements will be performed and test equipment (M\&TE) will be calibrated as specified in Procedure 033-YMP-QP 12.0, "Control of Measuring \& Test Equipment." See also Section 4.0 in this activity plan.

2. Test specimens will be procured as specified in Procedure 033-YMP-QP 4.0, "Procurement Document Control," and controlled as specified in Procedure 033-YMP-QP 8.0, "Identification and Control of Items, Samples, and Data."

3. Collected data will be controlled as specified in Procedure 033-YMP-QP 8.0, "Identification and Control of Items, Samples, and Data."

4. Scientific notebooks will be maintained as specified in Procedure 033-YMPQP 3.4, "Scientific Notebooks."

5. Technical reports will be prepared, reviewed, and approved as specified in Procedure 033-YMP-QP 3.3, "Review of Technical Publications." Technical data generated in this activity will be processed as specified in Procedure 033YMP-QP 3.6, "Collection, Review and Submittal of Technical Data," according to the kind of data and the desired disposition of the information. 


\subsection{Activity Close-out}

As with all other activities in the Metal Barriers task, the major reporting channel is through periodic revision of the Engineered Materials Characterization Report or EMCR, which is Activity E-20-39, in SIP-CM-01 Rev. 2. Supporting documentation such as scientific notebooks and technical report review comments will be retained by the appropriate individual (PI or technical support personnel) until the document package is transferred to the LLNL/YMP Local Records Center at the conclusion of these activities. Many of these records are transferred periodically as record segments so that the final records package of this activity is compiled over a period of time. QA records will be transmitted as described in Procedure 033-YMP-QP 17.0, "Quality Assurance Records."

No additional or special activity close-outs are planned.

\subsection{PRECISION AND ACCURACY}

\subsection{Calibration Requirements}

\subsubsection{Potentiostat and Electrochemical Test Cell}

As indicated in Section 3.4, potentiostats will be used as zero-resistance ammeters to measure current between two dissimilar materials immersed in a common electrolytic solution. An adequate calibration requirement for these potentiostats is their ability to generate the "polarization curve" described in the ASTM Standard entitled "Standard Reference Test Method for Making Potentiostatic and Potentiodynamic Anodic Polarization Measurements." This procedure is designated as ASTM G 5-94 (and will be called G 5 for short). To generate this curve, a specimen of AISI Type 430 stainless steel is exposed to a $1 \mathrm{~N}$ sulfuric acid solution, according to the detailed procedure given in this standard. This reference gives a permitted range of variation for positions of the curve along the potential and current density axes. The curve and the permitted range were developed after many years of experimental plots generated in various laboratories. This standard method will establish the limits of accuracy, precision, and tolerance for this activity.

This procedure is a self-calibration or confirmation of performance not only of the potentiostat but also of the external circuit. Thus, the $\mathrm{G} 5$ procedure is a check on the "system" consisting of the test cell solution, working electrode, counter electrode, reference electrode, Luggin probe, and connecting leads, as well as the internal circuitry, feedback functions, and power supply within the potentiostat unit. If the G 5 "curve" cannot be reproduced, the first thing to do is to check the components of the external circuit. The next step is to determine whether one of the "effects," such as the "crevice effect," "instrumental effect," or "oxygen effect," discussed in the appendix of G 5, is causing the discrepancy. The last step would be to determine whether there is a problem in the complex internal circuitry of the potentiostat, and this would require calibration of the voltage and current outputs by a qualified electronics laboratory or service.

A G 5 confirmatory test will be performed when using either a Model 273 or Model 283 potentiostat at the beginning of a series of galvanic corrosion experiments. If the series of experimental runs exceeds 30 , then another confirmatory test will be performed before the 3 lst run. The system may, of course, be calibrated by running the $\mathrm{G} 5$ test at more frequent intervals, as prescribed by the Lead Principal Investigator. User calibration of the system shall be documented in the scientific notebook. 
Reference electrodes will not have any calibration requirements. However, the reference electrodes will be inspected frequently for electrolyte level, blockage by gas bubbles, and obvious signs of deterioration. If in doubt, the reference electrode will be replaced by a new one, or the potential of the suspect electrode will be measured against a new one.

\subsubsection{Test Solutions}

Test solutions are made by weighing out a quantity of reagent and dissolving this quantity in the appropriate volume of water. The precision of the laboratory balance or other weighing device is not a critical issue, since the solution composition is a target, not a control. A commercial grade electronic balance, capable of weighing up to two decimal places (a hundredth of a gram) will provide more than adequate precision for this activity when operated in conformance with the manufacturer's instructions. Should an anomaly be suspected in the results, the operation of the balance can be confirmed by taring the balance to zero and confirming the weight of a known volume of water. An accuracy within $0.1 \%$ will provide adequate performance.

Solution pH is regularly measured in characterizing the test environment. Although a target $\mathrm{pH}$ is usually sought, the purpose of the measurement is not so much for control of the $\mathrm{pH}$ as it is to describe the environment. Standard laboratory $\mathrm{pH}$ meters or even indicator papers have sufficient accuracy for this purpose, since only accuracy to the integer value is needed. If a pH meter is used, it will be user-calibrated by use of known buffer solutions just prior to use and following the manufacturer's recommended procedure given in the operating manual. Any doubt about the performance of the $\mathrm{pH}$ meter or indicator paper is readily resolved by measuring standard $\mathrm{pH}$ buffer solutions.

\subsubsection{Other}

Such standard items as micrometers, scales, tape measures etc. , used to measure specimen dimension; flasks, beakers, graduated cylinders, pipettes, etc.to measure volumes; and thermometers, used to measure the temperature of the test cell do not require calibration. If there are any doubts about the accuracy of these items, measurement of a known dimension, known volume, or a physical standard (e.g. ice/water bath) will suffice in resolving the doubt.

\subsection{Sources of uncertainty and error to be controlled and measured}

The measured galvanic current, or the extent of observed galvanic attack will vary from sample to sample due to random variations in alloy composition, alloy microstructure, specimen surface micro-features, and other factors. Although these effects are usually small, replicate specimens will be tested to compare the generated data. It is expected that the calibrations and replications planned will control the effects of any conditions that could adversely affect results.

\subsection{IN-PROGRESS DOCUMENTATION}

Documentation to be generated during the conduct of this activity will include scientific notebooks, and may also include data record sheets, raw data, progress reports, and the final report. Scientific notebooks are controlled and maintained according to procedure 033-YMP-QP 3.4, "Scientific Notebooks." Test specimens will be controlled and maintained according to procedure 033-YMP-QP 8.0, "Identification and Control of Items, Samples, and Data." 
Analysis of data will be based on review of the data and on professional judgment, and the techniques used will be specified in the scientific notebook.

Along with other technical activities in the Metallic Barriers Task, reporting of the results of this activity will occur on a regular and periodic basis as determined by the schedule of project deliverables. Also, the results will be reported as revisions to the EMCR. As appropriate, topical LLNL reports (UCRL series) will be prepared on parts of this activity. Interim reports may also be written if deemed appropriate. The report(s) will undergo technical review as specified in procedure 033-YMP-QP 3.3, "Review of Technical Publications and Data."

\subsection{INTERFACES}

The information obtained from this experimental activity will assist activities in the following technical areas, and copies of the written reports from this activity will be distributed to the individuals designated:

(1) Metal Barrier Selection and Testing (SIP-CM-01)

R. D. McCright, TAL, Engineered Barrier Materials

(2) Waste Package Performance Assessment Activities (SIP-PA-2) W. Halsey, TAL, Performance Assessment

(3) Waste Package Basket Materials (SIP-CM-02) R. A. Van Konynenburg

\subsection{SCHEDULE}

The current PACS budget and schedule should be consulted.

\subsection{SPECIAL CASES}

No subcontractors are involved in these activities.

\subsection{REFERENCE}

ASTM Designation: G 5-94, "Standard Reference Test Method for Making Potentiostatic and Potentiodynamic Anodic Polarization Measurements." American Society for Testing and Materials 1995 Book of Standards, volume 3.01, pp. 48-58, ASTM, Philadelphia (1995)

\subsection{APPENDIX}

There are no appendices. 
Table 1

List of Materials Recommended for Testing

Commercial Name

Wrought Carbon Steel

CDA 715, 70/30 Cupronickel

Alloy 400, Monel 400

Alloy 825 , Incoloy 825

Hastelloy Alloy G-3

Hastelloy Alloy G-30

Hastelloy C-4, Alloy C-4

Hastelloy C-22, Alloy C-22

Titanium Grade-12
UNS Number

G10200

C71500

N04400

N08825

N06985

N06030

N06455

N06022

R53400
ASTM Number
A 516 Grade 55
B 171
B 127
B 425
B 581
B 581
B 575
B 574
B 265 Grade 12 


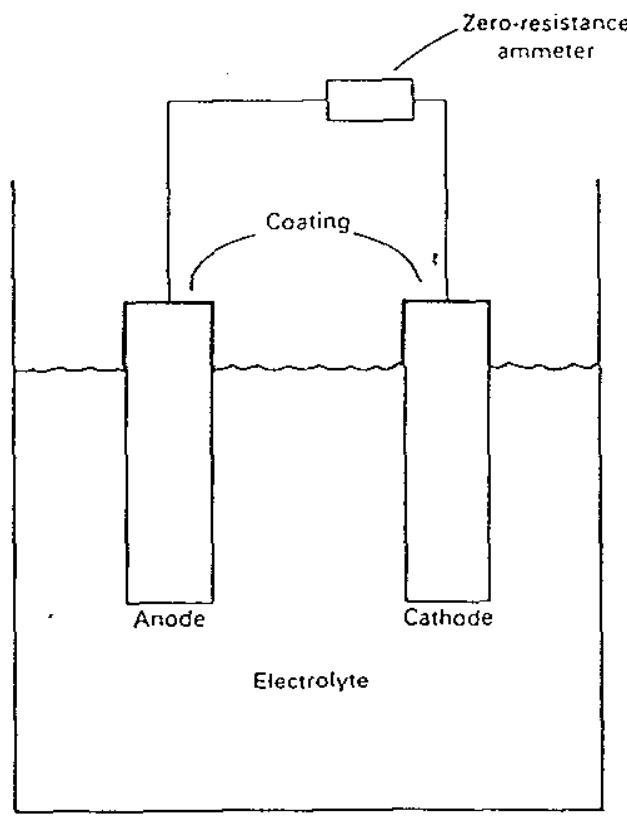

Figure 1. Electrochemical Test Setup to Measure Galvanic Current 
Lawrence Livermore

National Laboratory

YUCCA MOUNTAIN PROJECT

$$
\text { Page__ } 1
$$

Of $\quad 1$

\section{PLANNED TRAINING}

Activity \# E-20-46

\begin{tabular}{c|c|c|c|}
$\begin{array}{c}\text { Position for } \\
\text { Activity }\end{array}$ & $\begin{array}{c}\text { Person Filling } \\
\text { Position }\end{array}$ & $\begin{array}{c}\text { Training } \\
\text { Required }\end{array}$ & $\begin{array}{c}\text { Date for Completion } \\
\text { of Training }\end{array}$ \\
\hline EXAMPLE: & & & \\
\hline Technician & Ron Pletcher & QPs 6.0, 17.0, 13.0 & August 1993 \\
\cline { 2 - 4 } & & TIPS NF-03, NF-04 & Before Phase I \\
\hline
\end{tabular}

\begin{tabular}{|l|l|l|l|}
\hline Principle & Ajit Roy & QPs 3.0, 3.3, 3.4, 3.6, & \\
\cline { 3 - 4 } & & $4.0,5.0,6.0,7.0,8.0$, & \\
\hline $12.0,13.0,17.0$ & \\
\hline & & & \\
\hline & & & \\
\hline
\end{tabular}

\begin{tabular}{|l|l|l|l|}
\hline \multirow{3}{*}{$\begin{array}{l}\text { Senior } \\
\text { Technologist }\end{array}$} & Dennis Fleming & QPs 3.0, 3.3, 3.4.3.6, & \\
\cline { 3 - 4 } & & $4.0,5.0,6.0,7.0,8.0$, & \\
\hline & & $12.0,13.0,17.0$ & \\
\hline & & & \\
\hline & & & \\
\hline
\end{tabular}

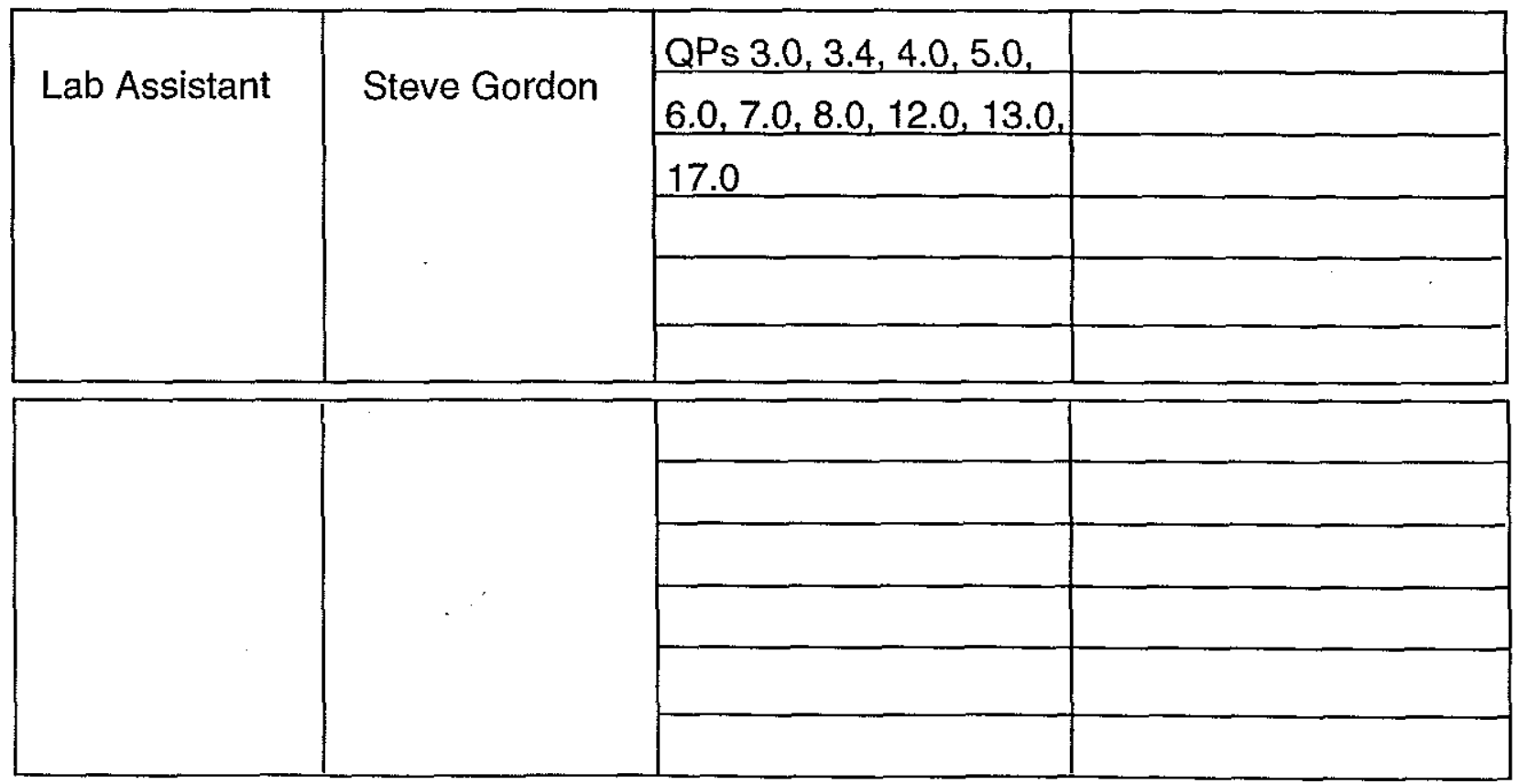


Lawrence Livermore

National Laboratory

YUCCA MOUNTAIN PROJECT

\section{PLANNED RECORDS}

Activity \# E-20-46

\section{Records to be Completed for this Activity}

No Yes

$\mathrm{X} \quad$ Publications (If yes, state how many and/or subject/title, if possible, milestone?)

Estimate 3-4 technical publications during the course of the activity. Also, activity provides input to EMCR updates (E-20-39).

$X \quad$ Technical Implementing Procedures to be written for this activity

(If yes, state how many and/or subject/title, if possible, milestone?)

Technical Data Input (If yes, state what type, and hold/transfer points for collection, milestone?)

Graphical and/or tabular data will be collected as per QP 3.6. 